\title{
Technology Innovation Stratagem and Role Played by MNCs: Evidence from Chinese Pharmaceutical Sector
}

\author{
Li-Li Cao ${ }^{1} \&$ Xiang-Dong Chen ${ }^{1}$ \\ ${ }^{1}$ The School of Economics \& Management. Bei Hang University, Beijing, 100083, P. R. China \\ Email:caolili31083125@sina.com
}

\begin{abstract}
It is widely regarded that the pharmaceutical sector is quite different from other manufactures for its character in innovation activities. This paper analyzed the nature of innovation activities by multinational companies (MNCs), which stand for foreign capital, focusing on two parameters named: size and scope of innovation through investigating patent data from 1985 to 2005. The paper reveals the role of the foreign capital and identifies their technology stratagem by developing a tool named Double-S Matrix. Research finding indicates that foreign capitals play an important role on overall national innovative competitiveness in this sector. Implications from this research can be used as reference to policy makers and business companies in China.
\end{abstract}

Keywords: size of innovation, scope of innovation, Double- S Matrix

\section{Introduction}

It is widely believed in international literature that innovation movement in pharmaceutical field is unique if one compares with other manufacture sectors. The major reasons for this are frequently listed as typical R\&D intensive sectors, more explicit knowledge based technologies, and one of the industries highly interdependent among larger MNCs and local SMEs in high tech sectors, especially, due to discontinuity nature in innovation process accompanied with emergence of bio-pharmaceutical technology in 1970's [7].

Technology development route in pharmaceutical industries thus can become more versatile or diversified, as Bogner and Thomas's work [4] indicated (as four different technology trajectories based on historical facts in pharmaceutical sectors in the US). Bogner and Thomas [4] therefore considered that strategic innovation and its classification were the major issues for firms in the industries, especially for larger MNCs. The sophisticated nature in innovation strategies in firms as well as in countries in the whole in pharmaceutical sectors can be best described by Hara's hypothesis [8]. He emphasized four basic forces regarding to input of $R \& D$ activities and outcome of the $\mathrm{R} \& \mathrm{D}$ process, namely, molecule-biological (technological) learning, interact factors during application process, market forces, and strategic roles of organizations.

The objective of this paper is to produce new empirical evidence pertaining to the characters of technology competition by MNCs. Based on patent data; this article holds several original features. Firstly, investigate the characters of innovator from a macro-level, data based on countries level was employed to reflect the innovation by
MNCs. Secondly, developed a tool to analysis the role of the foreign capital and reveal their stratagem.

\section{Literature Review and Research Frame- work}

\subsection{Innovation in the Pharmaceutical Sector}

Due to its exceptionally high $R \& D$ to sales, the pharmaceutical industry is often characterized as a technologyand science-driven sector. The radical innovation in drug industry is a function of the new technological and scientific knowledge embedded in the drug development [1]. The current research on innovation in the sector falls into four major aspects. Firstly, regional character is more significant in drug industry. Previous research shows that there is a intensive demand of regional proximity due to the science-based nature [12]. Secondly, it is a complex progress of innovation due to a long industry chain and diversiform actors. Most of scholars considered that innovation in the sector reflects breakthrough of innovation chain, which is also decided by the science-based character [10]. Thirdly, patents are a good measure of inventive activity [6]. The pharmaceutical sector has a high propensity to patent relative to other industries [17], also correlated with ratings of basic research excellence [18].

\subsection{Technology Competition Based Diversifica- tion}

There are many literatures to reveal the character of technology competition. Many of them focus on the two parameters: size and diversification, as well as their relationship [3]. It wildly believed that larger countries have a 
tendency to spread their research activities across many technological fields while small countries tend to concentrate on narrow niches. Later, Cantwell [7] used the data of 24 famous MNCs, focused on the size-diversification relationship has been stable over time or has changed in different historical periods, shows how the nature of this relationship has changed historically. Castaldi [6] analysis diversification patterns of Italian manufacturing firms, offered empirical evidence on a robust relationship between firm size and diversification. Breschi [5] analysis the diversification of innovation activates by identified two type of innovators: diversified innovators and specialized innovators . However, The theoretical and empirical literature has paid extensive attention to large firms' technological diversification of technology competition [11]; the equivalent phenomenon has been largely neglected and there are paucity of research at a country level.

\section{Empirical Methodology and the Data}

\subsection{Hypothesis}

In China, it is necessary for local firms to innovation to increase added value of products. It is important to study the innovation disciplinarian of the sector could promote industry's development and renew the structure of industry. However, the innovation disciplinarian must be influenced by foreign innovation activities because of the nature of FDI in China's pharmaceutical. This paper provides a research on the foreign patenting activities based on three main hypothesizes.

Hypothesis 1: Technology resource competition is determined at least by two parameters: size of technology and scope of technology.

Hypothesis 2: In Chinese pharmaceutical sector, there are two kinds of innovators, one is local firms and the other is MNCs invested by overseas capital. The two kinds of innovators interact with each other to control more technological resource. One side, they pursue the quantity of patent to ensure they have the expert advantage in certain field; the other side, they explore the technological scope to achieve the diversification effect.

Hypothesis 3: The diversification effect mainly comes from two aspects. One is from the diversification among the different product portfolio like the diversification between chemical preparations and biochemical medicines. The other is from the different process technology in producing a certain product. For example: the diversification between $\mathrm{C} 07 \mathrm{~K}$ and $\mathrm{C} 12 \mathrm{P}$ which both belong to the technology for biochemical medicines.

\subsection{The Empirical Methodology}

\section{Size of innovation}

It is not our objective to examine the overall effect of region size upon specialization in general (e.g. in new production and trade), but rather to concentrate on the innovation effort. Therefore, size here is related only to the technological activities carried out by regions in China's pharmaceutical sector. This paper measured innovation through the number of patent. However, patent data is a kind of count variable that obey the Poisson distribution. So we defined it in $\operatorname{size}_{i}=\log T P_{i}$ where $T P_{i}$ represents the accumulative patent in $i{ }^{\text {th }}$ period.

\section{Scope of innovation}

It is demonstrated that the entropy value is an effective measurement of the degree of diversification. This measure takes into account both the number of technologies in which a region might be active, as well as the relative distribution of technological activity across the technologies. Thus, this study will also utilize the entropy index to analysis the technological diversification among the sample in order to analysis the scope of technology resource. Therefore, we defined: entropy $y_{j}=\sum_{i=1}^{n} p_{i j} \ln \frac{1}{p_{i j}}$, where $p_{i j}$ in the present context represents the share of patents in China's pharmaceutical sector accounted for by the $i^{\text {th }}$ technology. The value of the entropy measure ranges between zero and $\ln n$, where a value of zero represents a region concentrating on one technology only and a value approaching $\ln n$ represents a region with an even distribution of patents.

One distinct advantage of using the entropy measure is its addictive properties. Specifically, the measure can be decomposed into elements, which define the contribution of technological diversification at various levels of aggregation to the total. The analysis in the present study makes use of the additive by examining technological diversification at two related level of aggregation.

The first level of aggregation follows the classification used by the China Patent Office, which make a distinction between 15 fields we selected such as A61K and C07D and so on. it is possible to distinguish between rather narrowly defined technological capability and diversification. It is a reflection of the total diversification both from the product various and process discrepancy. The second level aggregates the classes of technology into the 6 subsectors. In this classification, patents might fall into fields like biochemical medicines, Chemical preparations and so on. it could provide information about distribution of products among different regions. It is a proxy to reflect the scope of product technologies. Considering the addictive properties of entropy, the diversification of process technologies could be obtained as follow: entropy $_{i 2}=$ entropy $_{i T}-$ entropy $_{i 1}$, where the entropy ${ }_{i T}$ Stand for the entropy of total 15IPC classes, entropy Stand for the entropy of 6 sub-sectors which represent diversification of product, entropy ${ }_{i 2}$ Stand for the diversification of process technologies.

And the main body of diversification will be defined as 
the scope of technology:

$$
\text { scope }_{i}=\max \left\{\text { entropy }_{i 1} \text { entropy }_{i 2}\right\}
$$

In order to investigation the role of foreign capital in Chinese pharmaceutical sector, a hierarchical cluster was employed. In a hierarchical cluster problem, a set of sample ( $S=\left\{S_{i}, i=1,2, \ldots, n\right\}$ ) is to be clustered with respect to a set of criteria ( $C=\left\{C_{i}, i=1,2, \ldots, n\right\}$ ). Therefore, a $n \times m$ decision matrix can be obtained as

$$
X=\left[\begin{array}{cccc}
x_{11} & x_{12} & \ldots & x_{1 m} \\
x_{21} & x_{22} & \ldots & x_{2 m} \\
\cdots & \ldots & \ldots & \ldots \\
x_{n 1} & x_{n 2} & \ldots & x_{n m}
\end{array}\right]
$$

In this article $\mathrm{m}$ is 2 , and $\mathrm{n}$ could be 10 . Matrix $\mathrm{X}$ needs to be normalized as $Z_{i j}=\frac{X_{i j}-\overline{X_{j}}}{S_{j}}$ $i=1,2 \ldots .10 ; j=1,2 \quad i=1,2 \ldots .10 ; j=1,2$

As a consequence, a normalized decision matrix is obtained. Then the distance was defined by the Ward method. The finally step is take use of the SPSS software to obtain the consequents. It could cluster the sample into fixed clusters, which represent the different role of the foreign capital; it will correspond to the analysis by our tool named Size-Scope Matrix (Double-S Matrix). It is showed in Figure 1.

Tech-leaders usually distinguish themselves not only by possessing the highest size of patenting but also the broadest scope of patenting. According to this, they are companies with high potentials to dig the technology capabilities in a broad product scope. Tech-widen types are characterized by a comparative small size and broad scope. They represent that kind of samples that aim at expanding the width of the product technology scope and allocated their technology capabilities average among the scope.

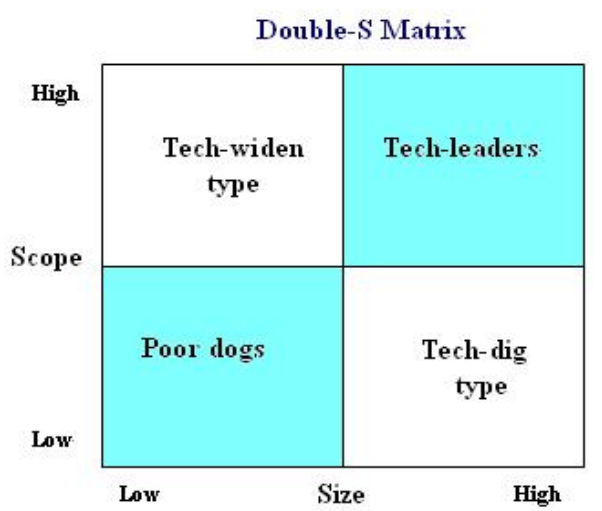

Figure 1. Double-S Matrix
Tech-dig types have a contrary nature compared to Tech-widen types. Samples belong to this type have a high enthusiasm in patenting in relative smaller scope. They aimed at digging a few kinds of technology lengthways to attain the specialized advantages. Poor dogs represent the samples that play a comparatively piddling role in Chinese pharmaceutical sector. They take a conservative attitude in patenting in China and invest inadequately.

\subsection{The Sample and Data}

Data based on countries level was employed to reflect the innovation by MNCs. Considered the character of the pharmaceutical sector which depend tightly on the government regulatory, historical period from 1985-2005 is then divided into four sub-periods which shows in Table 1.

15 IPC fields corresponding to pharmaceutical was selected which account for $82 \%$ of the total patent in the sector. The explanation of this technology field is list in Table 2; furthermore, the IPC classes were sorted related to industry classes, which are a sub-sector of pharmaceutical.

\section{The Analysis of the Results}

\subsection{Study on Size of Innovation}

Pharmaceutical sector is always thought to be a filed that attracts most FDI in china. Chen Xiangdong [19] investigated that the patent activities performed by FDI companies are most concentrated in Pharmaceutical sector. The patenting by foreign patenting is increasing over time as showed in Figure 2.

Thus, there are two main innovators in pharmaceutical

Table 1. the division of time periods

\begin{tabular}{|l|l|}
\hline period & \multicolumn{1}{|c|}{ Divided criterion } \\
\hline $1985-$ & $\begin{array}{l}\text { Patent Law Of The People's Republic Of China en- } \\
\text { tered into force in 1985 }\end{array}$ \\
\hline $1991-$ & $\begin{array}{l}\text { signed Memorandum of Understanding on the Pro- } \\
\text { tection of Intellectual Property, modified Patent Law } \\
\text { in 1992 }\end{array}$ \\
\hline $\begin{array}{l}1998- \\
2001\end{array}$ & $\begin{array}{l}\text { 21 of the top 25 international companies have set up } \\
\text { FDI companies in China }\end{array}$ \\
\hline $2002-$ & $\begin{array}{l}\text { China joined WTO formally on Dec. 11, the second } \\
\text { revision of patent law was put into practice. }\end{array}$ \\
\hline
\end{tabular}

Table 2. The technology fields

\begin{tabular}{|l|l|}
\hline industry classes & IPC Classifications \\
\hline chemical preparations & A61K \\
\hline medicinal chemicals & C07D, C07C, C07H \\
\hline biochemical medicines & C12N,C07K,C12P \\
\hline drug-like compounds & C08L,C08G,C01B,C08F \\
\hline pharmacy and Therapy & C12Q,A61B \\
\hline medical apparatus & A61F,A61M \\
\hline
\end{tabular}




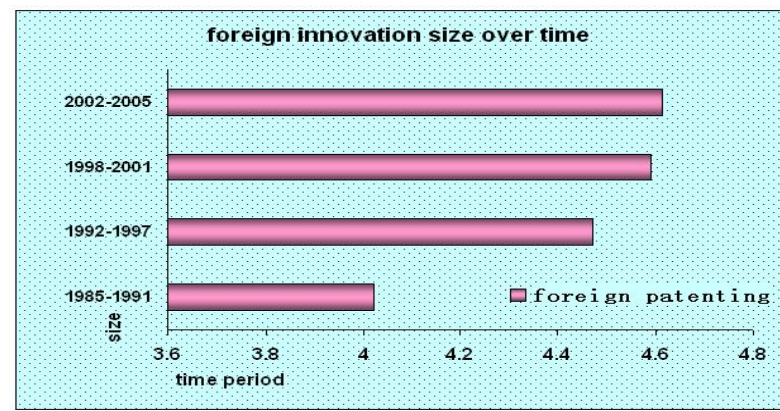

Figure 2. Foreign innovation sizes over time

sector, MNCs and local companies. It is essential to distinguish foreign patenting by FDI companies and local patenting by local companies, because it could not only indicate that the structure of innovation, but also identify major force of innovation in Chinese pharmaceutical sector. Evidence from data suggested that foreign patenting played an important part (percentage is $71 \%$, 64\%, 49\%, $42 \%$ over time), however, there is a decreasing tendency of foreign percentage over time. This tendency could not influence us to draw a judgment that it is lack of indigenous innovation capacity since critical technologies in half is controlled by foreign capital. The statistic evidence could not support the point that China has an advantage as Host County.

\subsection{Evolution Character of Scope of Innovation}

For the foreign capital, Fig 3.shows that there is a continuous increasing in diversification over time, while the counterpart shows an obvious fluctuation of indigenous patenting resource in pharmaceutical sector.

Evidence from the Wilcoxon Signed Ranks shows that there are positive changes among the four phases, however, the changes among the first three phases are positive but not significant (Sig. $=0.114$ ), only the technology scope of 2002-2005 period is significant changed to that of 1998-2001(Sig. =0.007). Investigate from the whole period; the increasing in scope is significant statistically (Sig. =0.013).

From the patent law passed to protection intelligence property right in 1985, foreign capital turned eyes to Chinese pharmaceutical market and take limited use of the law to protect their innovation for the shortage of the law. Therefore, the size and scope of foreign capital is smallest among the 4 periods. When China revised the patent law and implemented Regulation on Protection of Medicine, the Chinese medical market became regular gradually. Until 1998, twenty-one MNCs among the top 25 pharmaceutical ones had invested to China, mainly through founding overseas-invested enterprises to seize market; however, considerable part of their patenting is not produced in China. When China entered into WTO, it is more attractive for overseas capital because of China's signature on some related medical terms. Moreover, since the Danish corporation NovoNordisk set up R \& D center

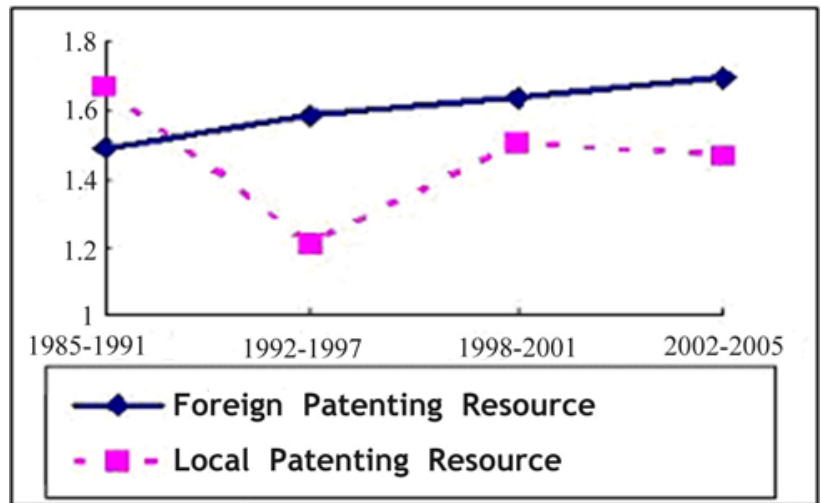

Figure 3. Scope of innovation over time

\begin{tabular}{|l|r|r|r|r|}
\hline & $\begin{array}{l}\text { Test Statistics } \\
\text { entropy2- } \\
\text { entropy1 }\end{array}$ & $\begin{array}{l}\text { entropy3- } \\
\text { entropy2 }\end{array}$ & $\begin{array}{l}\text { entropy4- } \\
\text { entropy3 }\end{array}$ & $\begin{array}{l}\text { entropy4- } \\
\text { entropy1 }\end{array}$ \\
\hline Z & $-1.580^{\mathrm{a}}$ & $-1.580^{\mathrm{a}}$ & $-2.701^{\mathrm{a}}$ & $-2.497^{\mathrm{a}}$ \\
Asymp.Sig.(2-tailed) & .114 & .114 & .007 & .013 \\
\hline
\end{tabular}

Figure 4. Results of Wilcoxon Signed Ranks. a: Based on negative ranks; b: Wilcoxon Signed Ranks Test

in BeiJing in 2002, it was followed by many other MNCs. It is obvious that MNCs turned investment on R\&D activities instead of operation activities. These R\&D centers have the liabilities to develop new drugs directly, which could enter more sub-sectors and seize patenting resource conveniently.

In the first three phases (1985-1991, 1992-1997, 19982001), foreign capital aimed mainly at market, therefore, they patent to keep their market shares. With China regulate the related laws step by step, foreign capital patent their technologies dramatically to pursue the advantage along the route of their existent products, In the latest phase (2002-2005), foreign capital aimed at acquisition of integrated advantage including not only about market shares, but also critical technologies. Changes of concept prompted MNCs entered more sub-sectors and enlarged their technology scope.

\subsection{Innovation Stratagem and Role Played by Foreign Capitals}

The further research is investigation about the role of overseas capital to identify their technology stratagem. According to the Double-S Matrix (Figure.1), the role of overseas capital could be analyzed in size and scope.

A Cluster method was employed to divide the samples into four clusters. If the center of gravity of each cluster falls into the four quadrants defined in the Double-S Matrix, it could confirm the validity of the Double-S Matrix. Employed the software (spss) to perform the hierarchical cluster, take the number of Cluster as four, then compute the four cluster's center of gravity to scatter them on the scatter plot of clusters, compare the result to the scatter plot of samples. 

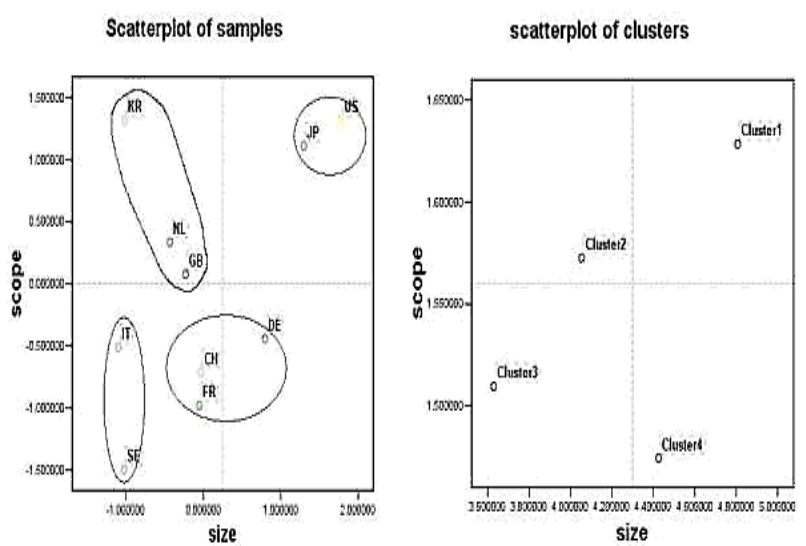

Figure 5. Comparative scatters

Figure 5 shows the result from the Cluster method is accordant with the four types defined by the Double $-\mathrm{S}$

Matrix. It is apparently that four clusters belong to four quadrants to confirm the validity of the Matrix. Hierarchical cluster offers a class statistically corresponding to the four roles defined by the Matrix. It is list in table 3 .

In Chinese pharmaceutical sector, America and Japan process the plentiful technology resource in most of the sub-sectors. They play a significant role as the tech-leader in patenting activities in Chinese pharmaceutical sector. Usually, they have absolutely advantage in most of the sub-sectors, while they have strength to carry out integrated innovation strategy to expand the width and depth of the technology. Tech - dig types with Represent of German, mainly concern about a few sub-sectors, which is important or familiar to them. They dig the potential technology capability with motivation to obtain the expert status and specialized technologies in some special subsectors which they have related competition advantage; therefore, they could capture monopoly profit by leading the dominant paradigm or establishing the technology criterion of these sub-sectors. Korea is the typical country, which belongs to the tech-width type, which has characters of using a relative smaller size to cover a relative broad scope of technology. They dabble in a broad filed and seize technology resource as broad as possible. They stimulate by diversified technology in order to achieve the scope economy, through integrating the operating and marketing of their diversified technologies and products. Refer to the poor dogs, they have a narrow scope and small size compare to the other three types. It could suggest that they hold a conservative attitude to the Chi nese pharmaceutical sector. However, they only keep the appropriate size and scope of technology to ensure their qualification to take part in this sector. If they have the expectation to seize the dominant technology in some sub-sector, they could increase their innovation activities to be tech-dig type. If there are business opportunities in many sub-sectors, they could implement a diversified stratagem to obtain profit.
Table 3. Role of foreign capital

\begin{tabular}{|l|l|l|}
\hline Cluster & Countries & \multicolumn{1}{c|}{ Type } \\
\hline Cluster 1 & America, Japan & Tech-leaders \\
\hline Cluster 2 & England, Holland, Korea & Tech-widen types \\
\hline Cluster 3 & Sweden, Italy & Poor dogs \\
\hline Cluster 4 & $\begin{array}{l}\text { Switzerland, France, } \\
\text { German }\end{array}$ & Tech-dig type \\
\hline
\end{tabular}

\section{Main Founding and Conclusion}

This paper investigated in the size and scope of technology as well as originally developing the double-S Matrix to distinguish the role of foreign countries, based on the patent data from 1985 to 2005. There are two main founding this paper achieves:

Firstly, foreign capital played a critical role in pharmaceutical sector in China, with respect to the size and scope over time. Secondly, there are four types of foreign capital defined by the double-S matrix. Accordingly, the largest countries, which called Tech-leaders, were always digging the technology capabilities in a broad product scope. While, smaller countries face two stratagems to select: technologically specialized in existed sub-sector with related comparative advantage, or expanding the product technology scope in a low technologically potential.

These findings carry some suggestions for public policy. Governments should understand that the role of the foreign capital. Public policy should be, therefore, tailored according to the condition. One side, the government should attract foreign capital to invest in China to obtain the technology transfer and other profit. According to the previous literature, the effect of technology transfer is depend on the absorb capabilities to a large distant, therefore, the new role of governments should be a "god father” to support education and training, public research and universities, and to encourage firms to invest in research. It will give indigenous innovation support, including finance to R\&D activities and special funds support. These actions could stand for public knowledge base; enhance the attraction of the region and development of China's pharmaceutical sector. Further, it will foster some pharmaceutical cluster, which embody MNCs in the innovation network, and make full use of the MNCs to pull the local innovation in the global economic.

\section{REFERENCES}

[1] Abernathy, W. J. and K. B. Clark. "Innovation: Mapping the winds of creative destruction." Research Policy 14(1), 1985, pp. 3-22.

[2] Arundel A., I. Kabla. What percentage of innovations are patented? Empirical estimates for European firms. Re- 
search Policy 27(2), 1998, pp. 127-141.

[3] Archibugi, D. and M. Pianta. "Specialization and size of technological activities in industrial countries: The analysis of patent data." Research Policy 21(1), 1992, pp. 79-93.

[4] Bogner, W. C. and H. Thomas, 《Drug to Market: Creating Value and Advantage in the Pharmaceutical Industry》, New York: Pergamon, 1996.

[5] Breschi, S., F. Lissoni, et al. "Knowledge-relatedness in firm technological diversification." Research Policy 32(1), 2003, pp. 69-87.

[6] Castaldi, C., M. Milakovic, et al. Scale and technological factors in the diversification structure of business firms. Economics Letters 91(1), 2006, pp. 117-121.

[7] Cantwell, J. and Vertova. Historical evolution of technological diversification. Research Policy 33(3), 2004, pp. 511-529.

[8] Hara, T., 'Industrial Technological Trajectories and Corporate Technology Traditions: the Development of Antibacterial Drugs in Japan', Annals of the School of Business Administration, Kobe University, 41, 1997, pp. 1-18.

[9] McMillan, G. S., F. Narin, et al. An analysis of the critical role of public science in innovation: the case of biotechnology. Research Policy 29(1), 2000, pp. 1-8.

[10] Marx, L. and M. R. Smith. Introduction [A ]. in M. R. Smith and L. Marx ( eds) , Does Technological Determinism [C ]. Cambridge,MA: M IT Press, 1994. pp. 9 - 15.

[11] Piscitello, L.. "Relatedness and coherence in technological and product diversification of the world's largest firms." Structural Change and Economic Dynamics 11(3), 2000, pp. 295-315.
[12] Swann, Peter and Prevezer, Martha. A Comparison of the Dynamics of Industrial Clustering in Computing and Biotechnology. Research Policy, 25(7), 1996, pp.1139-1157.

[13] Tushman, M.L., Anderson, P.C., 'Technological discontinuities and organizational environments', Administrative Science Quarterly, 31, 1986, pp.439-465.

[14] Tushman, M., P. Anderson. Technological discontinuities and organizational environments. Admin. Sci. Quart.31, 1986, pp. 439-465.

[15] von Zedtwitz, M. and O. Gassmann, "Market versus technology drive in R\&D internationalization: four different patterns of managing research and development, Research Policy 31(4), 2002, pp. 569-588.

[16] Zander, I. Technological diversification in the multinational corporation--historical evolution and future prospects. Research Policy 26(2), 1997, pp. 209-227.

[17] Taylor, C. T., Silberston, Z.A. The Economic Impact of the Patent System: a Study of the British Experience [M]. Cambridge University Press, Cambridge, 1973.

[18] Pavitt. Technology competencies in the world's largest firms: complex and path-dependent, but not much variety [J]. Research Policy, 26 (2), 1997, pp. 141-156.

[19] Chen xiangdong, Caolili, Comparative Study on indigenous Innovation resource in Pharmaceutical Fields: An Entropy Measure over Patent Data in China[C], international symposium on management of technology 2007, pp.817-821. 